PROF. MARÍA JOSÉ TORRES (Orcid ID : 0000-0001-5228-471X)

PROF. AXEL TRAUTMANN (Orcid ID : 0000-0001-6751-7328)

PROF. ANA M GIMÉNEZ ARNAU (Orcid ID : 0000-0001-9548-5423)

PROF. HYE-RYUN KANG (Orcid ID : 0000-0002-2317-4201)

DR. ESTHER MORENO (Orcid ID : 0000-0003-0953-3025)

PROF. KNUT BROCKOW (Orcid ID : 0000-0002-2775-3681)

Article type : EAACI Position Paper

\title{
TITLE: Practice Parameters for Diagnosing and Managing lodinated Contrast Media Hypersensitivity
}

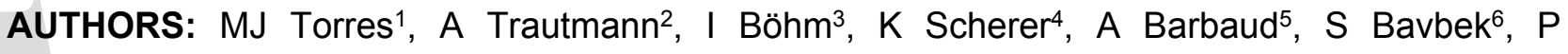
Bonadonna $^{7}$, J Cernadas $^{8}$, A Chiriac ${ }^{9}$, F Gaeta ${ }^{10}$, A M Gimenez-Arnau ${ }^{11}$, H Kang $^{12}$, E Moreno ${ }^{13}$, K Brockow ${ }^{14}$.

\section{AFFILIATION:}

${ }^{1}$ Allergy Unit, Regional University Hospital of Malaga-IBIMA-UMA-ARADyAL, Malaga, Spain. 2Department of Dermatology and Allergy, University Hospital Würzburg, Germany

${ }^{3}$ Department of Diagnostic, Interventional, and Pediatric Radiology, Inselspital, University of Bern, Switzerland

${ }^{4}$ Allergology, University Hospital Basel, Basel, Switzerland.

5Sorbonne Université, INSERM, Institut Pierre Louis d'Epidemiologie et de Sante Publique, APHP. Sorbonne Universite, Hopital Tenon, Service de Dermatologie et Allergologie, 4 rue de la Chine, 75020 Paris, France

${ }^{6}$ Ankara University, School of Medicine, Department of Chest Disease, Division of Immunology and Allergy, Ankara, Turkey

${ }^{7}$ Allergy Unit, Verona University Hospital, Verona, Italy.

${ }^{8}$ Department of Allergy and Immunology, Centro Hospitalar Universitário de S João, Porto, Portugal.

This article has been accepted for publication and undergone full peer review but has not been through the copyediting, typesetting, pagination and proofreading process, which may lead to differences between this version and the Version of Record. Please cite this article as doi: $\underline{10.1111 / \text { ALL. } 14656}$

This article is protected by copyright. All rights reserved 
9Department of Pulmonology, Division of Allergy, Hôpital Arnaud de Villeneuve, University Hospital of Montpellier, Montpellier, France.

${ }^{10}$ Allergy Unit, Columbus Hospital, Agostino Gemelli IRCCS University Hospital, Rome, Italy.

${ }^{11}$ Department of Dermatology. Hospital del Mar. IMIM. Universitat Autònoma Barcelona. Spain

${ }^{12}$ Division of Allergy and Clinical Immunology, Department of Internal Medicine, Seoul National University College of Medicine, Seoul, Korea

${ }^{13}$ Allergy Unit, University Hospital of Salamanca-IBSAL-UMA-ARADyAL, Salamanca, Spain ${ }^{14}$ Department of Dermatology and Allergy Biederstein, School of Medicine, Technical University of Munich, Munich, Germany.

\section{CORRESPONDING AUTHOR:}

Maria Jose Torres, Research Unit for Allergic Diseases. UMA-IBIMA-Hospital Regional Universitario de Málaga. PI. Hospital Civil, 29009 Malaga, Spain. mjtorresj@uma.es. Phone +34 951290224. FAX +34951290302.

WORD COUNT: 6347 words

Conflict of interest: None of the authors has any conflict of interest.

\section{ABBREVIATIONS:}

ICM: lodinated contrast media; IHR: immediate hypersensitivity reaction; NIHR: non-immediate hypersensitivity reactions; MPE: maculopapular exanthema; SJS: Stevens-Johnson syndrome; TEN: toxic epidermal necrolysis; FDE: fixed drug eruption; DRESS: drug reaction with eosinophilia and systemic symptoms; SDRIFE: symmetric drug-related intertriginous and flexural exanthema; AGEP: acute generalized exanthematous pustulosis; DPT: drug provocation test; IGDA/ENDA: EAACI IG Drug Allergy/European Network on Drug Allergy; EAACI: European Academy of Allergy and Clinical Immunology; ST: skin tests; BAT: basophil activation tests; SPT: skin prick test; IDT: intradermal test; NPV: negative predictive value; cysLT: cysteinyl leukotrienes; eGFR: estimated glomerular filtration rate; LTT: lymphocyte transformation tests; PT: patch testing. 


\section{ABSTRACT}

Immediate and non-immediate hypersensitivity reactions to iodinated contrast media (ICM) have been reported to occur in a frequency of about $0.5-3 \%$ of patients receiving non-ionic ICM. The diagnosis and management of these patients varies among guidelines published by various national and international scientific societies, with recommendations ranging from avoidance or premedication to drug provocation test. This position paper aims to give recommendations for the management of patients with ICM hypersensitivity reactions and analyze controversies in this area.

Skin tests are recommended as the initial step for diagnosing patients with immediate and nonimmediate hypersensitivity reactions; besides, they may also help guide on tolerability of alternatives. Reexposition or drug provocation test should only be done with skin test-negative ICMs. The decision for performing either reexposition or drug provocation test needs to be taken based on a risk-benefit analysis. The role of in vitro tests for diagnosis and pretreatment for preventing reactions remains controversial.. 


\section{INTRODUCTION}

Adverse events after iodinated contrast media (ICM) administration may be either hypersensitivity reactions (type $B$ reactions) or toxic reactions (type $A$ reactions) $(1,2)$. According to the time interval between ICM administration and appearance of symptoms, hypersensitivity reactions are divided into immediate reactions (IHR), which occur within 1 to $6 \mathrm{~h}$ after ICM administration, or non-immediate reactions (NIHR), appearing more than $6 \mathrm{~h}$ after ICM exposure (2-5). Both IHR and NIHR have been reported to occur in a frequency of about $0.5-3 \%$ of patients receiving nonionic ICM (3).

IHR induce anaphylaxis, urticaria, angioedema, sometimes together with vomiting, abdominal pain, diarrhea, or more severe reactions affecting the respiratory and cardiovascular systems presenting with dyspnoea, bronchospasm and/or a sudden drop in blood pressure (2-7). Hypotension may be associated with loss of consciousness (anaphylactic shock). In about $70 \%$ of these reactions, the onset is within 5 min after injections (8).

NIHR commonly manifest as maculopapular exanthema (MPE), and rarely as more severe reactions such as Stevens-Johnson syndrome (SJS), toxic epidermal necrolysis (TEN), fixed drug eruption (FDE), drug reaction with eosinophilia and systemic symptoms (DRESS), symmetric drug-related intertriginous and flexural exanthema (SDRIFE), or acute generalized exanthematous pustulosis (AGEP) $(2,3,5-7,9)$. In addition, delayed appearing urticaria or angioedema may occur, especially within the first 6 hours after ICM administration.

The management of patients with previous hypersensitivity reactions to ICM varies among guidelines published by various national and international scientific societies, with recommendations ranging from avoidance or premedication to drug provocation test (DPT) $(3,10$, 11) (Table 1). This position paper aims to give recommendations for the management of patients with ICM hypersensitivity reactions and analyze controversies in this area. It updates previous recommendations by the EAACI IG Drug Allergy/European Network on Drug Allergy (IGDA/ENDA) taking into account new data and developments (3).

\section{METHODS}

This position paper was commissioned by the European Academy of Allergy and Clinical Immunology (EAACl). It is based on evidences as well as on expert opinion. The preparation included a literature search in MEDLINE by the members of the Task Force Group focusing on the search of the words (radio and iodinated) contrast hypersensitivity, adverse reactions, hypersensitivity, and allergy. We restricted the content of this paper to hypersensitivity reactions. During the development of these guidelines, the consultation process included meetings in Amsterdam in April 2018, in Munich in May 2018, in November 2018 in Zurich, a telephone 
conference in November 2018, and in June 2019 in Lisbon. Comments, suggestions, and recommendations were carefully considered and consented by the whole group. For each statement, the quality of evidence and recommendation was graded and discussed, confirmed, or amended by consensus of the Task Force members. Grading for key statements was performed adopting the GRADE system (12). Evidence was graded as high, low, or very low based on expert opinion considering available evidence, because no systematic review was done. The strength of the recommendations was strong or weak, that is, the grading of low/strong in the text denotes a low quality of evidence or great strength of recommendation.

\section{IMMEDIATE HYPERSENSITIVITY REACTIONS}

The mechanism underlying IHRs to ICM is still a matter of controversy (6) and, although in the majority of patients the mechanism is non-allergic, in some cases IgE-mediated allergic reactions are reported $(6,13-16)$. The presence of positive skin tests (ST) and basophil activation tests (BAT), and older studies reporting detection of low levels of specific IgE to ionic ICM indicate an IgE-mediated mechanism $(6,13-21)$. Histamine and tryptase serum levels $(15,19,20)$, as well as the frequency of positive allergy diagnostic tests, increase with the severity of the reaction $(6,10$, $13,20,21)$. A recent multicentre prospective study documented allergy in one in tenth, a quarter, half and all patients with cutaneous, moderate-systemic, life threatening anaphylaxis and cardiac arrest, respectively (20). The risk for IgE-mediated allergy increases when three or four different organs are affected simultaneously, especially when cardiovascular symptoms appear in combination with respiratory or cutaneous reactions (20). In contrast, non-allergic reactions are likely when only one organ is affected $(20,21)$.

IHRs in the context of a contrast-enhanced image-guided procedure are in most cases (74\%) contrast media-induced reactions (22). In the remaining $26 \%$, other culprit substances/cases such as latex, adenosine, or vasovagal reaction could be identified (22).

\section{1.- What are indications for testing?}

a) Background: The most significant risk factor for an IHR to a ICM is a previous immediate reaction. Other presumed risk factors (gender, asthma, atopy, allergy to other drugs) (23) have shown inconsistent results and therefore cannot be used as pre-requisite for performing ICM allergy work-up.

b) Practical statement: Allergy testing is indicated in patients with history of IHR. There are no indications for testing patients labelled as "iodine allergy" (povidone iodine, crustaceans, and mollusk) as well as patients with food, respiratory, cutaneous, drug allergies, but no previous reaction to ICM. Besides, it is not indicated in patients with unspecific symptoms (generalized 
pruritus, heat sensation, transient erythema, flushing, dizziness, nausea, sneezing, rhinorrhea, chest tightness) or localized cutaneous reaction (isolated wheals, erythema) at the ICM injection site.

\section{Recommendations}

- To perform allergic work-up in patients with a history of ICM-induced anaphylaxis (strong/moderate).

- To perform it in patients with a history of ICM-induced isolated urticaria, angioedema, or bronchospasm (weak/low).

\section{2.- How to perform skin testing?}

a) Background: IHRs to ICM have traditionally been perceived as non-allergic reactions (24), therefore ST has been considered as an inappropriate tool for the diagnosis of such reactions, although this view has changed by newer evidence (25). The sensitivity of STs in IHR varies from $4.2 \%$ to $73 \%$ among different studies $(6,13,26-30)$. A meta-analysis revealed positive rates of $17 \%(95 \% \mathrm{Cl}, 10-26 \%)$, being up to $52 \%(95 \% \mathrm{Cl}, 31-72 \%)$ for severe reactions (29). In a large study, positive STs were observed in $26 \%$ of patients reporting IHR; $3 \%$ had positive skin prick test (SPT) and $25 \%$ positive intradermal test (IDT) (6). The specificity of SPT is estimated at $94.6 \%$ and of IDT $91.4 \%-96.3 \%(6,30)$. Negative predictive value (NPV) of ST with ICM has been reported to be $93 \%$ (95\% confidence interval, $86-96 \%)$ in a meta-analysis (29). A French study reported high NPV of skin testing for ICM $(94.2 \%(95 \% \mathrm{Cl} 89.6 \%$ to $97.2 \%)$ for IHR) (21). Only one Spanish study reported that only $62.5 \%$ of their patients were diagnosed by ST and $37.5 \%$ by drug provocation test (DPT) (26). In the same centre, NPV were $97.3 \%$ or $80 \%$ when DPT was done by injecting $10 \mathrm{~mL}$ or $50 \mathrm{~mL}$, respectively (31).

Such variability may be due to patient selection, , the clinical symptoms of the patients, their severity, the ICM substance used, the time between the reaction and the study and that DPT cannot differentiate allergic from non-allergic IHR as it is the case with other drugs (32-34). If this time is within 2-6 months, $50 \%$ of patients tested show positive results, decreasing to up $18 \%$ for patients tested at other time points (earlier than 2 months or later than 6 months) (6). The reason for this fact may be the limited duration of skin reactivity due to IgE clearance (35).

b) Practical Statement: SPT and IDT should be performed according to EAACI Guidelines (36). ICM should be used undiluted at the iodine concentration of $300-320 \mathrm{mg} / \mathrm{ml}$ for SPT and diluted 1:10 for IDT $(5,6)$. STs should be performed with the ICM involved in the reaction, if known (5, 10 ), as it has been reported that $56.7 \%$ (37) to $86 \%$ of patients with positive STs gave positive 
results to the culprit (6). It has been reported that a total of $18.2 \%$ were positive to two ICM and $27.3 \%$ to three or more (6). Therefore, STs should be performed with the broadest possible panel of ICM available in the department if the result is positive, or if the culprit is unknown $(5,10)$.

\section{Recommendations}

- When to test: STs are preferably performed within 2-6 months after the reaction (weak /low).

- What to test: STs should be performed with the ICM involved in the reaction if known (strong /high). If the result is positive, or if the culprit ICM is unknown, STs should be performed with the broadest possible panel of ICM (strong /moderate).

- How to test: ICM should be used undiluted at 300-320 mg/ml for SPT and diluted at 1:10 for IDT (strong /moderate). STs should start by performing SPT and, if negative, continue with IDT (strong/moderate).

\section{3.- What is the value of in vitro testing?}

There are different in vitro methods used in IHR to ICM: histamine, tryptase, and cysteinyl leukotrienes (cysLT) determination at the acute phase of the reaction, and BAT for identifying the ICM involved in the reaction once the reaction has resolved.

\subsection{Histamine, tryptase, and cysteinyl leukotrienes}

a) Background: Histamine is released from mast cells and basophils after IgE-mediated reactions and concentrations measured in plasma few minutes after reactions correlate with severity. Histamine can also be released from basophils in vivo through non-IgE-mediated pathways (14, $15,38)$. Tryptase is continually secreted by mast cells in tissues, and then it diffuses into the circulation, where it can be measured as protryptase. This can undergo additional processing within the cell to become mature tryptase, which is secreted only during mast cell activation. De novo synthesized cysLT may also mediate ICM-induced IHR (39).

b) Practical Statement: Histamine and tryptase can be both measured to confirm IHR to ICM. However, histamine is degraded quickly, being less specific and more complicated to measure by commercially available assays. Thus, tryptase is regarded as the preferred mediator. The approach is to compare acute (within $4 \mathrm{~h}$ of the event) and baseline total tryptase levels (at least $24 \mathrm{~h}$ after all signs and symptoms of the event have subsided) to distinguish between an increased mast cell burden (e.g., mastocytosis, in which baseline tryptase levels remain elevated) and mast cell degranulation (with only acute tryptase levels elevated). The minimal elevation of acute over baseline tryptase levels suggested to be clinically significant is calculated as at least 2 $\mathrm{ng} / \mathrm{ml}+[1.2 \times$ baseline tryptase level] (40) or at least $20 \%$ above baseline plus $2 \mathrm{ng} / \mathrm{mL}$ during or within $4 \mathrm{~h}$ after a symptomatic period (41). An increase from baseline level during allergic symptoms is suggestive of an IHR to ICM. It has been reported that higher tryptase elevations are 
indicative of IgE-mediated mast cell activation and correlate with the clinical severity of the reaction $(15,20,42)$.

\section{Recommendation}

Tryptase determination at the acute phase is useful for confirming IHR to ICM, if a transient increase is detectable (strong /moderate).

\subsection{Basophil activation tests}

a) Background: BAT is a flow cytometry-based cellular assay that measures activation of basophils upon allergen stimulation. It has shown utility for diagnosing IHR to drugs $(28,43)$. Regarding ICM, three studies demonstrate a BAT sensitivity of $46-63 \%$ depending on the threshold chosen, and a specificity of $89-100 \%(13,26,44)$. The area under the ROC curve was $0.79(95 \%$ confidence interval $0.67-0.91, p<0.0001)$ by using the stimulation index as the diagnostic criteria with 1:100 dilution of RCM (44).

b) Practical Statement: BAT can be a complementary tool to diagnose IHR to ICM (5), showing good correlation with ST and DPT results (26). It may be especially useful in cases with severe reaction and contraindications for ST or DPT (5). It is important to take into account that certain factors may affect BAT result, such as the time between the reaction and the test or the severity and type of reaction (26). However, the NPV has not been clearly determined (45). In addition, it has to be considered that about $10 \%$ of patients have non-reacting basophils (positive-control negative), rendering this test unsuitable for these patients.

\section{Recommendation}

- BAT can be an additional tool for diagnosing patients with IHR with severe reactions or those with high risk (weak /low).

\section{4.- Is there a role for Drug Provocation Test?}

a) Background: DPT is the final step of the diagnostic algorithm because of potential risk to the patient and it is used when there is no other available diagnostic tool. Moreover, it can be used to find a safe alternative. However, controversy still exists about the need of DPT with ICM, with most studies coming from Europe $(10,21,26,31,32,37,46,47)$. In the American Guidelines there is no statement favouring DPT with ICM in IHRs (48). Studies from Japan indicated severe reactions to very small "pre-test doses" (49), which has hampered development of DPT for many years. Even in patients without reaction to "pretesting", severe reactions have been reported following ICM-re-exposure (50). However, these older studies used pretesting not after skin 
testing as a tool for risk stratification prior to re-exposure; therefore, potential IgE-mediated allergic patients were left unidentified. New studies seem to indicate that DPT could be a safe procedure, presenting the same risks as with other drugs when higher doses are used and it is performed in experienced centres $(10,13,26,32)$.

Administration of ICM is potentially harmful. Besides hypersensitivity reactions, they can induce contrast-induced acute kidney injury, which may lead to end-stage renal disease and even death, thyrotoxic crisis, and lactic acidosis. Therefore, only trained allergists who adhere to necessary safety recommendations should perform DPTs with ICM.

b) Practical Statement: Either reexposition in a needed radiologic examination or DPT can be done either to confirm tolerance with the ST negative culprit ICM or with an ST-negative alternative ICM in patients with positive ST to the culprit ICM, or in patients with an anaphylactic reaction in which administering the culprit is contraindicated $(5,9)$. A DPT should be considered in very severe IHRs.

A broad safety check is necessary in every patient who will undergo DPT with ICM, especially in patients with kidney risk factors. It is recommended to determine the serum creatinine, to calculate the estimated Glomerular Filtration Rate (eGFR) and to monitor these parameters after DPT. DPT is contraindicated in patients with risk factor for kidney injury and renal insufficiency, in patients who receive nephrotoxic medication, in patients with contrast-enhanced image guided examination less than one week ago, or in whom a diagnostic contrast administration is planned in the next 1-7 days. DPT is also contraindicated in patients who will undergo a radioiodine therapy as well as in patients with hyperthyroidism. Pregnant and breast-feeding women should be excluded from DPT. Metformin medication should be stopped $24 \mathrm{~h}$ before the DPT, and can be reintroduced if the follow-up does not reveal a renal function alteration. As prophylaxis against renal damage it is recommended to give low-osmolality or isosmolar ICM and check renal function before injection (27).

As with other drugs, there is no consensus regarding the dose of ICM during DPT, with doses ranging from 49 to $100 \mathrm{~mL}$. The protocols are: (i) $5-15-30-50 \mathrm{~mL}$ (cumulative dose $=100 \mathrm{~mL}$ ) at 45-min intervals (26); (ii) 0.05-0.5-1-5-7.5-10-25 mL (cumulative dose $=49.05 \mathrm{~mL}$ ) at 30- $\mathrm{min}$ intervals (51).

\section{Recommendations}

- Either reexposition or DPT can be performed to confirm tolerance to a skin test-negative ICM; the decision is based on availability of DPT and risk-benefit analysis (strong/high).

- DPT with ICM can be done as a diagnostic test either with the culprit or with an alternative ICM (strong/high).

This article is protected by copyright. All rights reserved 
- Available protocols should be standardized and validated (strong /high).

- Renal function needs to be carefully monitored (strong/high).

- As in any DPT, the decision need to be taken based on a risk-benefit analysis of each patient and should be done only in well-equipped centres and by trained personnel in immediate emergency treatment (strong /low). The possibility to perform the DPT together with the radiological examination should be considered (strong /low).

- DPT is not indicated in patients at risk (renal complaints, hyperthyroidism, radioactive iodine therapy, pregnant and breast-feeding women, nephrotoxic medication, etc.) (strong/high).

\section{5.- How should a patient be evaluated?}

a) Background: Patients with a history of an IHR to ICM may react again upon renewed administration of ICM (52). But in cases reporting a mild ICM-induced IHR limited to the skin, the risk of developing moderate to severe anaphylaxis after re-administration of ICM is below $1 \%$ (53).

b) Practical Statement: The most important step in the evaluation of an IHR to ICM is a thorough history in order to establish the severity of the reaction. An isolated urticarial skin reaction represents a mild IHR, and anaphylactic shock is the most severe form. Allergy work-up for (presumably IgE-mediated) immediate-type, allergic ICM hypersensitivity includes SPT undiluted, IDT with a dilution of at least 1:10 (highest sensitivity), BAT (facultative), and DPT (if needed). Unfortunately, at present only a minority of patients with ICM-induced IHR undergo allergy testing and, therefore, in many patients ICM are re-administered without prior testing.

Moreover, in clinical practice the culprit ICM is often unknown, as documentation in radiology and cardiology departments is often restricted to the total volume of the injected ICM, whereas the exact name of the ICM is not always mentioned. Premedication with $\mathrm{H}_{1}$ antihistamines and corticosteroids may prevent recurrence in mild to moderate immediate reactions $(5,54)$. However, as premedication has not been shown beneficial in moderate/severe IHR and corticosteroids might induce substantial side effects, its use is becoming more and more controversial and applying an alternative skin test-negative ICM without premedication is a valid option and may perhaps become the standard in the future, after more experience is being generated (55)

\section{Recommendations (Fig 1)}

- All patients with ICM-induced IHR should undergo allergy testing in order to diagnose or exclude ICM allergy and to identify a safe ICM alternative (strong/low).

This article is protected by copyright. All rights reserved 
- If STs are negative there is no evidence for an ICM allergy, rather for a non-allergic ICM hypersensitivity, which is mostly mild to moderate in severity. The options are to give an alternative ICM with premedication or to perform a DPT to confirm tolerability.

- As an approach for patients with a convincing history of ICM-induced IHR (no allergy testing yet), in which ICM-based radiological imaging is urgently needed, these steps can be followed:

(i) If IHR is limited to the skin, i.e. urticaria with or without angioedema: ICM can be administered after pre-medication (strong/high). If the culprit ICM is known, an alternative ICM should be used.

(ii) Moderate to severe IHR (full-blown anaphylaxis): omit ICM and perform native computed tomography (CT)- or magnetic resonance (MR)-scan instead; if ICM is indispensable, administer the ICM after pre-medication and in anaesthesia stand-by (strong/low). If the culprit ICM is known, an alternative ICM should be used (strong/high).

\section{6.- When is premedication recommended?}

a) Background: Premedication with systemic corticosteroids and $\mathrm{H} 1$-antihistamines has been widely used to reduce the rate of IHR although its effectiveness has not been properly documented and there is no gold standard of premedication regimens. Moreover, premedication is not able to suppress all IHRs and some patients may develop breakthrough reactions.

Usually, the premedication protocol consists in a combination of a multidose corticosteroid and an antihistamine (e.g. prednisone $13 \mathrm{~h}, 7 \mathrm{~h}$ and $1 \mathrm{~h}$ prior to ICM exposure with diphenhydramine $1 \mathrm{~h}$ prior to ICM exposure) (56-58). Lee et al. (54) reported the result of a study to evaluate the benefit of a severity-tailored prophylaxis in patients at risk of recurrent hypersensitivity reactions to ICM. Chlorpheniramine and methylprednisolone were recommended according to a severity index, and an alternative ICM based on a negative ST was used for patients with near-fatal anaphylactic shock or life-threatening reactions. In the group of patients with mild reactions, the prophylaxis with antihistamines plus corticosteroids did not produce significant beneficial outcomes compared with pretreatment with only antihistamines. However, in patients with severe reactions, the frequency of breakthrough reactions was reported to decrease when patients were premedicated with chlorpheniramine and corticosteroids two and 12 hours before. In general, using an alternative ICM protected for developing a reaction. They recommended that for patients with mild reactions, antihistamines can be a safe alternative option on re-exposure, and that the steroid dose should be stratified according to the severity of the previous reaction. However, the benefit of adding $\mathrm{H} 2$-antihistamines is not sufficiently demonstrated, and they are not routinely administered (59-61). Moreover, corticosteroid premedication has been discussed to be associated with substantial costs and indirect harm related to length-of-stay prolongation in inpatients (62).

This article is protected by copyright. All rights reserved 
The minimal interval for premedication administration is unknown. A 12-h or 13-h oral scheme of corticosteroids is usually recommended but an accelerated intravenous scheme is proposed when the multidose schedule is not feasible $(54,55)$.

Premedication has not been considered sufficient and might not even be indicated in patients with a history of true IgE-mediated ICM anaphylaxis $(55,63,64)$. Lee et al. observed 6/9 selected high-risk patients to be ST positive (54), and Marshall et al. observed 2/10 positive DPTs (60), indicating a subgroup of type I allergic patients.

Currently, some American and European associations suggest changing ICM within the same class of low-osmolar ICM $(58,65)$. Several recent studies have demonstrated that changing ICM in mild reactions to low-osmolar ICM reduced the rate of breakthrough reactions $(54,66,67)$. Some authors found that changing the ICM was more effective than premedication in prevention of recurrence reactions (66). Others found that the recurrence rate of mild IHR was $31.1 \%$ when patients were re-exposed to the same ICM without premedication (67). When the ICM was changed, the recurrence rate of IHR was $12 \%$ and with the addition of antihistamine premedication the rate was $7.6 \%$.

b) Practical Statements: Some American associations advise premedication for all patients with an "allergic-like" or unknown-type contrast reaction (57). However, European guidelines (65) recently removed the suggestion of invariably using premedication in patients at risk and emphasized the need to undergo an allergy evaluation to confirm or exclude an IgE-mediated drug allergy to ICM and to identify safe alternatives. They advised to change the ICM when it is known, since the use of an alternative ICM has proven more helpful in reducing the rate of recurrent IHR to ICM $(54,66)$. If the culprit ICM is unknown and there is an urgent need for ICM, premedication with $\mathrm{H} 1$ antihistamines and corticosteroids may prevent recurrence in mild to moderate immediate reactions $(5,56,57)$.

In patients with a history of a prior severe reaction, re-administration of ICM is a relative contraindication, but if necessary and in the absence of alternatives, premedication should be considered, although evidence for efficacy is lacking in high-risk patients. In patients with a history of moderate-to-severe reaction, a higher dose of corticosteroids than usually used could be considered (54).

\section{Recommendation}

- Premedication is not a general recommended approach (high/strong).

- In cases the culprit ICM is unknown and ICM administration is needed premedication could be an option (weak /low).

\section{NON-IMMEDIATE HYPERSENSITIVITY REACTIONS}


NIHR to ICM range from unspecific and toxic symptoms (such as local pain or local wheal at the injection site, generalized pruritus, transient erythema, dizziness, nausea) to severe cutaneous adverse reactions. These latter reactions are mainly T-cell mediated, in skin biopsies a perivascular infiltrate of CD4+ and CD8+ T-cells has been uniformly demonstrated, and positive delayed STs are common. Recently, it has been demonstrated that DRESS syndrome due to ICM occurs with a very short delay, within the week following the ICM injection (68). Positive lymphocyte transformation tests (LTT) and ICM-specific T-cell clones have been demonstrated in some patients (69). The immunological reaction in patients with NIHR is directed against the structure of the ICM and not against the iodine ion in the vast majority of patients. NIHR to ICM are characterized by a T-cell mediated mechanism, appearing from hours to days after administration of the ICM. Delayed appearing non-allergic urticaria and/or angioedema occurring $>6$ hours after ICM administration seem to be caused by a different, poorly understood mechanism.

Non-ionic dimeric ICM induce significantly more often cutaneous NIHRs than non-ionic monomeric ICM (70). In fact, more than $50 \%$ of MPE are induced by the non-ionic dimeric ICM iodixanol (71).

\section{1.- What are the indications for testing?}

a) Background: As for IHR, NIHR to ICM may vary from uncomplicated MPE to complex hypersensitivity reactions such as DRESS or severe and life-threatening bullous drug reactions such as SJS/TEN. The most frequent clinical manifestation is mild to moderate MPE $(3,6,9,10$, 27, 69). A history of a previous ICM-induced adverse reaction is a predisposing factor for NIHR.

b) Practical statement: Allergy testing is indicated in patients with clinical history indicative of MPE, FDE, SDRIFE, or AGEP. In severe bullous skin reactions and in DRESS, ST is recommended, whereas DPT is generally contraindicated, although even in these cases exceptions are possible depending on the risk of a renewed severe reaction and urgent need. Although the mechanisms underlying delayed-appearing urticaria and angioedema are not well understood, they should be studied.

\section{Recommendations}

- To identify patients with T cell-mediated reactions to ICM and to provide guidance on tolerability of alternatives, all patients with a suspicion of ICM-induced exanthema should be tested (strong/moderate).

- Delayed-appearing urticaria and angioedema are usually ST-negative (weak /low).

\section{2.- How to perform skin testing?}

This article is protected by copyright. All rights reserved 
a) Background: An immunological, T-cell mediated mechanism has been demonstrated for the various clinical manifestations of NIHR by delayed reading IDT and patch test (PT), immunehistological findings, and specific proliferation of T-cells in vitro $(5,72-74)$. STs can be helpful to identify the responsible ICM and to find alternative $\operatorname{ICM}(3,5,6,20,21,27,29,37,46,69,72,75$, 76). In a European multicentre study, 98 patients with NIHR to ICM were investigated by SPT, IDT, and PT using the suspected culprit and a variety of other ICM of all four chemical subgroups (6). STs with delayed reading were positive in $38 / 98$ patients $(38 \%, 95 \% \mathrm{Cl} 28-47 \%)$, with $32 \%$ being positive in the IDT with late reading, $28 \%$ in the PT, and only $3 \%$ in the SPT with delayed reading, some patients tested positive in only one test. A meta-analysis on STs in hypersensitivity reactions to ICM found the overall positive rate for STs in NIHR to be $26 \%$ (95\% CI, $15-41 \%$ ), for SPT 7\% (95\% Cl, 1-30\%), for IDT 22\% (95\% Cl, 13-34\%), and for PT 16\% (95\% Cl, 9-26\%), and an added value if IDT and PT were combined and the suspected culprit was included (29). No false-positive STs were found in six European studies on NIHRs. If four or more ICM were tested, ST-negative ICM were detectable in $90 \%$ of cases $(95 \% \mathrm{Cl} 77-96 \%)$ (29). IDT performed between 1 and 6 months after the resolution of the hypersensitivity reactions showed higher positive rates $(48 \%)$ than if later performed $(23 \%, p=0.02)(6)$. IDTs are generally carried out at 1:10 dilutions for IHR and NIHR, but up to $70 \%$ of IDT reacted to the undiluted ICM with good safety without generating false positive IDT and it may be used if the immediate reading of the 1:10 dilution is negative (69). For SCARs however, where very little information on ST is available, it is not advisable to proceed directly to undiluted ICM in IDT, and a safe stepwise approach starting with PT, followed by IDT 1:10, and finally IDT 1:1 in which for each step delayed reading is performed prior to proceeding to the next step, should be considered.

Regarding the NPV of STs, whereas two older smaller studies had reported a lower NPV $(69,72)$, a meta-analysis and larger studies performed afterwards highlighted the usefulness of STs for identifying safe alternatives $(21,29,77)$, and a NPV of $86.1 \%$ (IC95\%: 72.1-94.7\%) has been calculated in the largest study (21). Milder flare-up reactions upon IDT in NIHR seem to be rare, but possible (72).

b) Practical Statement: For IDT, 1:10 dilutions of the standard ICM solution are non-irritative (6). However, the sensitivity of IDT with delayed reading in NIHR seems to be higher if undiluted ICM concentrations are used (69). In that case, the frequent difficulty to interpret immediate reaction needs to be ignored as it does not represent a sign of an immediate IgE-mediated allergy. IDT with undiluted ICM may induce irritative large uncoloured wheals after 20 minutes without surrounding erythema, possibly due to the osmolarity of the products, which may be difficult to distinguish from a positive IDT (large wheal with a surrounding erythema). IDTs should ideally include a first reading after 48 hours and a second one after 72 hours (6). For PT, ICM can be 
tested undiluted. PTs should have two readings: at the moment of removal (after 48 hours), and a delayed reading $72-120$ hours later (6). Due to the possibility of later appearance of skin reactions, patients should be instructed to report any skin reaction at the test site.

Some patients with FDE or SDRIFE might exhibit negative STs, if tested only on the upper arms or upper back. In FDE testing should be done at the previous involved area by in situ PT (78). A potential explanation could be the presence of drug specific resident memory T-cells at the site of the clinical reaction, which seem to be more reactive upon local challenge (skin testing) than central memory T-cells (79).

Allergological work-up should be ideally performed within 6 months after the clinical reaction since sensitivity of the tests is reduced thereafter (69).

\section{Recommendations}

- When to test: ideally within the first 6 months after the clinical reaction and more than 6 months in case of DRESS (weak /low).

- What to test: ideally the suspected culprit and several commonly used alternatives due to the extended cross-reactivity in NIHR (strong/moderate). In DRESS and FDE, patch tests can be useful and SPT and IDT should not be used (weak /low).

- How to test: IDT with 1:10 dilution of the standard concentration of ICM or undiluted on the upper arm or upper back with delayed reading after 48 and 72 hours (weak /low). PT on the upper back with undiluted standard solution of ICM with reading at 48 hours and a delayed reading (72-120 hours) (strong /low). Patients should be instructed to return for additional readings in case of any later appearing skin reaction at the test site (weak/low). Using both tests may enhance sensitivity (weak /low). If all tests are negative: Consider IDT and/or PT with undiluted ICM in local testing, especially in FDE (weak /low).

\section{3.- What is the value of the Lymphocyte Transformation Test?}

a) Background: LTT measures the proliferation of T-cells after stimulation with a drug in vitro. It aims to detect circulating drug-specific memory T-cells, which proliferate upon drug (= antigen) stimulation. In most cases, proliferation is measured as ${ }^{3} \mathrm{H}$-thymidine uptake as counts per minutes (cpm). Generally, results are given as stimulation index in relation to unstimulated cells. The sensitivity and specificity of the LTT must be newly defined for each antigen. It has been used to demonstrate specific recognition of ICM by T lymphocytes in patients with $\operatorname{NIHR}(73,74)$. LTT results in NIHR to ICM are heterogeneous and the sensitivity ranges from 13 to $75 \%$, variability probably related to the number of patients studied, their clinical characteristics, the diagnostic approach used, and the expertise of the diagnostic laboratory (80). LTT can only be considered as an additional tool and taking into account that a negative LTT cannot rule out a 
NIHR (5). b) Practical Statement: LTT is not recommended at the acute stage, but rather after 48 weeks after remission (81) and within 2-3 years after the reaction (82). Corticosteroids in doses higher than $0.2 \mathrm{mg} / \mathrm{kg}$ body weight prednisone equivalent and other immunosuppressive or immunomodulatory agents may interfere with the test. A NPV for LTT in NIHR to ICM is not available. As radioactive materials have been banned in many laboratories the use of "modified non-radio-active LTT" will be a better choice.

\section{Recommendations}

- The LTT can be done as an additional diagnostic tool in selected cases with contraindications for STs (weak /low).

- It should only be performed by experienced physicians (weak /low).

\section{4.- Is there a role for DPT?}

a) Background: DPT with ICM can be necessary to rule out the diagnosis and to identify alternative ICM that can be used in subsequent radiological examinations, if hypersensitivity to ICM is confirmed $(5,26,46,69,72,83)$. The ICM chosen for DPT will depend on ST results and reaction severity. The polyvalent reactivity seems higher in $\operatorname{NIHR}$ than in $\operatorname{IHR}(6,13,21,37,69$, $74,80)$. The most frequently association has been found between iodixanol and iohexol $(6,37$, $69)$, and between ioversol and iomeprol (21).

b) Practical Statement: DPT with the culprit ICM may rule out the diagnosis of NIHR in patients with non-severe reactions, and with an alternative in patients with confirmed NIHR or with severe reactions (3). It has been reported that DPT identified NIHR to ICM in up to $41.7 \%-56.4 \%$ of negative ST patients $(69,72)$. It has been reported that iobitridol shows low cross-reactivity in patients with NIHR to other ICM (76).

Several modalities of DPT with ICM have been reported with no consensus regarding the total dose or intervals of DPT, e.g.: (i) increasing doses at 1-h intervals in two runs separate by 1 week (5-10-15 mL on the first day and 20-30-50 mL (cumulative dose: $100 \mathrm{cc}$ ) on the second day) (10); (ii) 5-20 mL of iobitridol at 1-hour interval and two $50 \mathrm{~mL}$ doses at 1-hour interval (cumulative dose: $100 \mathrm{~mL}$ ) the following week (76); (iii) 1/100 of the dose required for radiological examination and 1-24 $\mathrm{h}$ later $1 / 10$ of the dose required (37, 72); (iv) $0.05-0.5-1-5-7.5-10-25 \mathrm{~mL}$ at $30-\mathrm{min}$ interval $(13,51)$. In patients with NIHR, premedication is not effective $(84,85)$.

\section{Recommendations}

- DPT with ICM can be necessary to confirm the diagnosis or to identify a safe alternative ICM (weak/low).

This article is protected by copyright. All rights reserved 
- The ICM chosen for DPT may be the culprit in patients with non-severe reactions and negative ST, and a ST-negative alternative in patients with confirmed NIHR or with severe reactions (weak/low).

- Renal function need to be carefully monitored (strong/high).

- Available protocols should be standardized (strong/high).

\section{How should a patient be evaluated}

a) Background: MPE developing several (mostly 6-12) hours after administration seems to account for the great majority of $\operatorname{NIHR}(6,69,86)$. An exanthematous skin eruption is classified as uncomplicated MPE if signs of a systemic reaction such as fever, hepatitis or nephritis are virtually absent. In addition, single cases of FDE, flexural exanthema, AGEP and even lifethreatening DRESS, SJS and TEN have been described as $\operatorname{ICM}$-induced $\operatorname{NIHR}(3,7,80)$.

b) Practical statement: In ICM-related MPE, allergy testing is mandatory to reliably confirm or exclude ICM as cause of the skin rash. It should be borne in mind that only few patients with MPE show a positive test result. Otherwise, many patients may be unjustified labelled as ICM allergic. In non-severe MPE, the moderate sensitivity and high specificity of STs (performed within 6 months after the clinical reaction) for diagnosis of allergic NIHR in combination with a limited risk (reoccurrence of a MPE) implies that diagnostic DPT is often not necessary. In patients sensitized to several ICM, DPT may be advisable to prove that a certain ST-negative ICM is definitely tolerated (69).

\section{Recommendations (Fig. 2)}

- The first and most important step in the evaluation of patients with suspected ICM-induced NIHR is a thorough history (high/strong).

- An uncomplicated MPE should be clearly separated from other clinical reaction patterns (high/strong).

- If there are hints in history or medical documents suggesting a morphologically unusual skin eruption, a systemic reaction including hepatitis or nephritis, or a bullous skin reaction with mucosal involvement, diagnostic testing (ST and DPT) must be based on individual risk-benefit considerations or is even contraindicated (high/strong).

- The evaluation of patients with ICM-associated MPE should include IDT and PT ensuring that patients with allergic ICM hypersensitivity are not missed (low/strong). Moreover, skin testing may identify alternative ICM, which are tolerated in DPT and in future radiological investigations (low/strong).

This article is protected by copyright. All rights reserved 
- If clinical history, information from treating physicians, caregivers or medical records unambiguously indicate an uncomplicated MPE and there is an urgent diagnostic need, ICM may be administered based on individual risk-benefit considerations (low/weak).

\section{6.- When is premedication recommended?}

a) Background: No studies have systematically evaluated the use of premedication for prevention or recurrences of NIHR. Although it has been indicated that corticosteroids premedication in patients with previous NIHR to ICM may be useful (57), repeated reactions, including a case of TEN, have been described $(3,84,86,87)$.

b) Practical statements: There is no evidence for a premedication in patients with NIHR and this can be especially harmful in patients with a history of a severe NIHR (e.g. TEN, DRESS).

\section{Recommendation}

There is no evidence to prove the efficacy of premedication in patients with NIHR to ICM (high/strong).

\section{OPEN QUESTIONS FOR IMMEDIATE AND NON-IMMEDIATE REACTIONS}

\section{1.- Is there any cross-reactivity among ICM?}

Currently, it is not clear whether 'cross-reactivity' does exist or not and further studies are needed. In clinical studies, multiple reactions are regularly observed, in $67 \%$ of the 97 patients having at least one positive ST with ICM, STs and re-administration of other ICM may induce reaction (37). In studies with smaller populations, it varies a lot: from $20 \%$ ( $n=15)(88), 26 \%(n=$ 15) $(72), 27 \%(n=22)(69), 43 \%(n=80)(21)$ to $75 \%(n=36)(6)$. Cross-reactivity is neither related to iodine, nor to excipients contained in ICM, nor to their ionicity. In NIHR, cross reactions could be related to the presence of the carbamoyl side chain in some ICM. Hasdenteufel et al. (75) reported that only 2 of 22 patients sensitized to iodixanol also reacted to iobitridol. In NIHR Gracia-Bara et al. (89) also observed a very few numbers of reactions between iobitridol and other ICM. Preferential multiple reactions are summarized in Table 2.

\section{Recommendation:}

- Further studies are needed to understand better multiple reactions against ICM (strong /moderate).

\section{2.- What else in the management?}

Radiologists should be prepared to recognize and treat the various types of adverse reactions to ICM, including anaphylaxis. In a retrospective analysis of radiologist practice over a five-year 
period, adrenaline was only used in 9 out of 457000 cases, being laryngeal oedema the most frequent symptom $(\mathrm{N}=6)(90)$. Only $41 \%$ of radiologists gave the correct treatment of adrenaline to an IHR (91). Similar studies indicated lacking radiology resident preparedness for paediatric life-threatening events (92). Thus, radiologists' use of adrenaline should be improved by training. Computerized guidelines for the detection and management of patients with ICM hypersensitivity reactions have proven to be effective not only in gaining epidemiological data, but also in standardizing the management and reducing adverse events in patients with previous ICM hypersensitivity reactions $(93,94)$.

There has been a concern that IHR to ICM might be more common in systemic mastocytosis (SM), as patients with SM frequently develop anaphylaxis to several triggers $(95,96)$. However, there is no evidence that there is a greater risk of IHR to ICMs in patients with SM compared with the general population. Only few individual cases with IHR to ICMs have also been described in patients with SM and SM has not ever been reported as an underlying disease in patients with fatal RCM-induced anaphylaxis (97). Nevertheless, in all patients with previous anaphylaxis to ICM, baseline serum tryptase should be determined to screen for mastocytosis. Additionally, patients with SM should also undergo allergy testing to ICMs. Before administering ICMs to adults with mastocytosis, emergency preparedness is necessary and resuscitation facilities should be nearby.

\section{Recommendations}

- Radiologists should improve emergency awareness and training on emergency treatment of ICM IHR (high/strong).

- In all patients with previous anaphylaxis to ICM, baseline serum tryptase should be determined to screen for mastocytosis (low/weak).

- Emergency preparedness is needed before administering ICMs to adults with mastocytosis, and resuscitation facilities should be nearby (low/weak).

\section{CONCLUSIONS}

Hypersensitivity reactions to ICM are still a challenge. It is pivotal to have a good clinical history, but also to evaluate the medical record for discordances, uneventful re-expositions that might help the choice for a safe ICM. STs are recommended to identify patients with IgE- or T cellmediated reactions to ICM and to provide guidance on tolerability of alternatives. BAT can be an additional tool for diagnosing patients with IHR with severe reactions or those with high risk. LTT for NIHR may be an alternative when STs cannot be performed. DPT is the gold-standard but the decision for performing it needs to be taken based on a risk-benefit analysis of each patient and 
should be done only in well-equipped centres and by trained personnel. There is no evidence of the efficacy of premedication in patients with severe IHR, IgE-mediated reactions, and NIHR to ICM. Further studies are needed to better understand multiple reactions against ICM. Allergist should convince patients and physicians of the usefulness of critically evaluating the ICM allergy label(s) early-on.

Table 1. Management of patients with previous hypersensitivity reaction to ICM

\begin{tabular}{|c|c|c|c|c|}
\hline Management & Advantages & Disadvantages & Comment & Ref \\
\hline Avoidance & Safety & Diagnosis not achieved & $\begin{array}{l}\text { To be considered in } \\
\text { patients in which other } \\
\text { diagnostic options (e.g. } \\
\text { magnet resonance } \\
\text { tomography) are } \\
\text { applicable }\end{array}$ & $(3,5)$ \\
\hline Premedication & Easy & $\begin{array}{l}\text { Breakthrough reactions } \\
\text { in patients with severe } \\
\text { previous reactions } \\
\text { False sense of security } \\
\text { No evidence for benefit } \\
\text { No consensus on } \\
\text { standard regime } \\
\text { Risk of side effects } \\
\text { (corticosteroids) } \\
\text { Expense of effort and } \\
\text { medication }\end{array}$ & $\begin{array}{c}\text { Is not recommended } \\
\text { because there is no } \\
\text { enough evidence of its } \\
\text { effectiveness } \\
\text { Probably not helpful for } \\
\text { preventing severe } \\
\text { allergic HR } \\
\text { Often done in the USA } \\
\text { but considered } \\
\text { controversial in Europe }\end{array}$ & $\begin{array}{c}(52-62, \\
98)\end{array}$ \\
\hline $\begin{array}{l}\text { Alternative by } \\
\text { Clinical History }\end{array}$ & $\begin{array}{l}\text { Easy } \\
\text { Reduction of } \\
\text { reaction rates }\end{array}$ & Weak evidence & $\begin{array}{l}\text { Use of different ICM } \\
\text { more effective } \\
\text { compared with } \\
\text { premedication } \\
\text { Difficult to identify the } \\
\text { culprit ICM in clinical }\end{array}$ & $(66,67)$ \\
\hline
\end{tabular}

This article is protected by copyright. All rights reserved 


\begin{tabular}{|c|c|c|c|c|}
\hline & & & $\begin{array}{c}\text { records } \\
\text { Cross-reactivity may } \\
\text { exist }\end{array}$ & \\
\hline $\begin{array}{l}\text { Alternative by } \\
\text { ST-negativity }\end{array}$ & $\begin{array}{c}\text { High negative } \\
\text { predictive value } \\
\text { Exclusion of ICM } \\
\text { highly suspected } \\
\text { not to be tolerated } \\
\text { Severe anaphylaxis } \\
\text { unlikely when a ST- } \\
\text { negative ICM is } \\
\text { taken }\end{array}$ & $\begin{array}{c}\text { Time consuming } \\
\text { Expertise needed } \\
\text { Only few patients with } \\
\text { IHR will have positive } \\
\text { ST } \\
\text { More useful in NIHR } \\
\text { No prediction for non- } \\
\text { severe non-allergic } \\
\text { reactions }\end{array}$ & $\begin{array}{l}\text { Increasing evidence } \\
\text { Recommended in } \\
\text { Europe by allergists }\end{array}$ & $\begin{array}{l}(21,29, \\
32,37, \\
46,47, \\
51,69, \\
76,77, \\
83,92)\end{array}$ \\
\hline $\begin{array}{l}\text { Alternative by } \\
\text { DPT-negativity }\end{array}$ & $\begin{array}{l}\text { Approach when } \\
\text { ICM administration } \\
\text { is needed } \\
\text { ICM dose can be } \\
\text { titrated }\end{array}$ & $\begin{array}{c}\text { Time consuming } \\
\text { Hospitalization } \\
\text { necessary } \\
\text { Expertise needed also } \\
\text { for emergency treatment } \\
\text { Risk stratification } \\
\text { needed }\end{array}$ & $\begin{array}{l}\text { Increasing evidence } \\
\text { that DPT is safe } \\
\text { Previously avoided } \\
\text { because of severe } \\
\text { reactions when } \\
\text { radiologists used } \\
\text { pretest dosages }\end{array}$ & $\begin{array}{l}(10,26, \\
51,69, \\
77,89)\end{array}$ \\
\hline
\end{tabular}

This article is protected by copyright. All rights reserved 
Table 2. Data on reported cross-reactivity of ICM in NIHR (adapted from (37)).

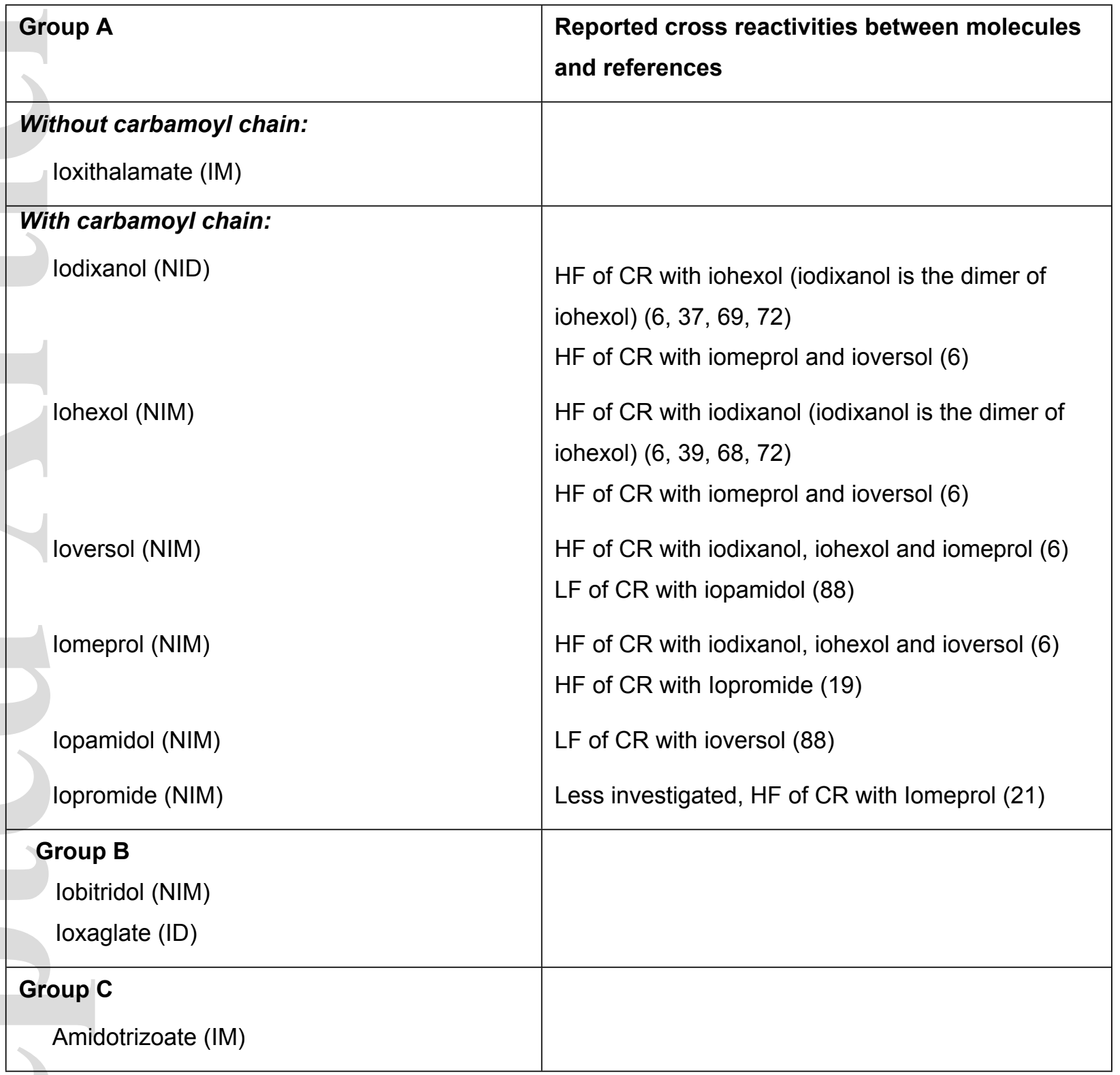

IM: ionic tri-iodized monomer, NIM: non-ionic tri-iodized monomer, ID: ionic hexa-iodized dimer, NID: nonionic hexa-iodized dimer, HF: high frequency, CR: cross reactivity, LF: Low frequency.

1. Brockow K, Ring J. Classification and pathophysiology of radiocontrast media hypersensitivity. Chem Immunol Allergy 2010;95:157-169. 
2. Böhm I, Heverhagen JT, Klose KJ. Classification of acute and delayed contrast mediainduced reactions: proposal of a three-step system. Contrast Media Mol Imaging 2012;7(6):537541.

3. Brockow K, Christiansen C, Kanny G, Clement O, Barbaud A, Bircher A, et al. Management of hypersensitivity reactions to iodinated contrast media. Allergy 2005;60(2):150-158.

4. Tanno LK, Torres MJ, Castells M, Demoly P, Joint Allergy A. What can we learn in drug allergy management from World Health Organization's international classifications? Allergy 2018;73(5):987-992.

5. Brockow K. Medical algorithm: Diagnosis and treatment of radiocontrast media hypersensitivity. Allergy 2020;75(5):1278-1280.

6. Brockow K, Romano A, Aberer W, Bircher AJ, Barbaud A, Bonadonna P, et al. Skin testing in patients with hypersensitivity reactions to iodinated contrast media - a European multicenter study. Allergy 2009;64(2):234-241.

7. Brockow K, Ardern-Jones MR, Mockenhaupt M, Aberer W, Barbaud A, Caubet JC, et al. EAACI position paper on how to classify cutaneous manifestations of drug hypersensitivity. Allergy 2019;74(1):14-27.

8. Katayama H, Yamaguchi K, Kozuka T, Takashima T, Seez P, Matsuura K. Adverse reactions to ionic and nonionic contrast media. A report from the Japanese Committee on the Safety of Contrast Media. Radiology 1990;175(3):621-628.

9. Böhm I, Schild HH. A practical guide to diagnose lesser-known immediate and delayed contrast media-induced adverse cutaneous reactions. Eur Radiol 2006;16(7):1570-1579.

10. Rosado Ingelmo A, Dona Diaz I, Cabanas Moreno R, Moya Quesada MC, Garcia-Aviles C, Garcia Nunez I, et al. Clinical Practice Guidelines for Diagnosis and Management of Hypersensitivity Reactions to Contrast Media. J Investig Allergol Clin Immunol 2016;26(3):144155; quiz 142 p following 155.

11. Morcos SK, Thomsen HS, Webb JA, Contrast Media Safety Committee of the European Society of Urogenital R. Prevention of generalized reactions to contrast media: a consensus report and guidelines. Eur Radiol 2001;11(9):1720-1728. 
12. Atkins D, Eccles M, Flottorp S, Guyatt GH, Henry D, Hill S, et al. Systems for grading the quality of evidence and the strength of recommendations I: critical appraisal of existing approaches The GRADE Working Group. BMC Health Serv Res 2004;4(1):38.

13. Trcka J, Schmidt C, Seitz CS, Brocker EB, Gross GE, Trautmann A. Anaphylaxis to iodinated contrast material: nonallergic hypersensitivity or IgE-mediated allergy? AJR Am J Roentgenol 2008;190(3):666-670.

14. Laroche D, Aimone-Gastin I, Dubois F, Huet H, Gerard P, Vergnaud MC, et al. Mechanisms of severe, immediate reactions to iodinated contrast material. Radiology 1998;209(1):183-190. 15. Laroche D. Immediate reactions to contrast media: mediator release and value of diagnostic testing. Toxicology 2005;209(2):193-194.

16. Mita H, Tadokoro K, Akiyama K. Detection of IgE antibody to a radiocontrast medium. Allergy 1998;53(12):1133-1140.

17. Dewachter P, Mouton-Faivre C, Felden F. Allergy and contrast media. Allergy 2001;56(3):250-251.

18. Böhm I, Speck U, Schild HH. Pilot study on basophil activation induced by contrast medium. Fundam Clin Pharmacol 2011;25(2):267-276.

19. Brockow K, Vieluf D, Puschel K, Grosch J, Ring J. Increased postmortem serum mast cell tryptase in a fatal anaphylactoid reaction to nonionic radiocontrast medium. J Allergy Clin Immunol 1999;104(1):237-238.

20. Clement O, Dewachter P, Mouton-Faivre C, Nevoret C, Guilloux L, Bloch Morot E, et al. Immediate Hypersensitivity to Contrast Agents: The French 5-year CIRTACI Study. EClinicalMedicine 2018;1:51-61.

21. Schrijvers R, Breynaert C, Ahmedali Y, Bourrain JL, Demoly P, Chiriac AM. Skin Testing for Suspected lodinated Contrast Media Hypersensitivity. J Allergy Clin Immunol Pract 2018;6(4):1246-1254.

22. Böhm I, Alfke H, Klose KJ. Hypersensitivity reactions and contrast medium injection: are they always related? Eur J Radiol 2011;80(2):368-372.

23. Worm M, Francuzik W, Renaudin JM, Bilo MB, Cardona V, Scherer Hofmeier K, et al. Factors increasing the risk for a severe reaction in anaphylaxis: An analysis of data from The European Anaphylaxis Registry. Allergy 2018;73(6):1322-1330. 
24. Johansson SG, Bieber T, Dahl R, Friedmann PS, Lanier BQ, Lockey RF, et al. Revised nomenclature for allergy for global use: Report of the Nomenclature Review Committee of the World Allergy Organization, October 2003. J Allergy Clin Immunol 2004;113(5):832-836.

25. Brockow K. Immediate and delayed reactions to radiocontrast media: is there an allergic mechanism? Immunol Allergy Clin North Am 2009;29(3):453-468.

26. Salas M, Gomez F, Fernandez TD, Dona I, Aranda A, Ariza A, et al. Diagnosis of immediate hypersensitivity reactions to radiocontrast media. Allergy 2013;68(9):1203-1206.

27. Kvedariene V, Martins P, Rouanet L, Demoly P. Diagnosis of iodinated contrast media hypersensitivity: results of a 6-year period. Clin Exp Allergy 2006;36(8):1072-1077.

28. Mayorga C, Fernandez TD, Montanez MI, Moreno E, Torres MJ. Recent developments and highlights in drug hypersensitivity. Allergy 2019;74(12):2368-2381.

29. Yoon SH, Lee SY, Kang HR, Kim JY, Hahn S, Park CM, et al. Skin tests in patients with hypersensitivity reaction to iodinated contrast media: a meta-analysis. Allergy 2015;70(6):625637.

30. Goksel O, Aydin O, Atasoy C, Akyar S, Demirel YS, Misirligil Z, et al. Hypersensitivity reactions to contrast media: prevalence, risk factors and the role of skin tests in diagnosis--a cross-sectional survey. Int Arch Allergy Immunol 2011;155(3):297-305.

31. Soria A, Masson N, Vial-Dupuy A, Gaouar H, Amsler E, Chollet-Martin S, et al. Allergological workup with half-dose challenge in iodinated contrast media hypersensitivity. Allergy 2019;74(2):414-417.

32. Prieto-Garcia A, Tomas M, Pineda R, Tornero P, Herrero T, Fuentes V, et al. Skin testpositive immediate hypersensitivity reaction to iodinated contrast media: the role of controlled challenge testing. J Investig Allergol Clin Immunol 2013;23(3):183-189.

33. Fernandez TD, Torres MJ, Blanca-Lopez N, Rodriguez-Bada JL, Gomez E, Canto G, et al. Negativization rates of IgE radioimmunoassay and basophil activation test in immediate reactions to penicillins. Allergy 2009;64(2):242-248.

34. Gomez E, Blanca-Lopez N, Torres MJ, Requena G, Rondon C, Canto G, et al. Immunoglobulin E-mediated immediate allergic reactions to dipyrone: value of basophil activation test in the identification of patients. Clin Exp Allergy 2009;39(8):1217-1224. 
35. Boehm I. Limited duration of hypersensitivity reactions to contrast and exact documentation of such adverse events. Reg Anesth Pain Med 2020;45(3):246.

36. Brockow K, Romano A, Blanca M, Ring J, Pichler W, Demoly P. General considerations for skin test procedures in the diagnosis of drug hypersensitivity. Allergy 2002;57(1):45-51.

37. Lerondeau B, Trechot P, Waton J, Poreaux C, Luc A, Schmutz JL, et al. Analysis of crossreactivity among radiocontrast media in 97 hypersensitivity reactions. J Allergy Clin Immunol 2016;137(2):633-635 e634.

38. Laroche D, Gomis P, Gallimidi E, Malinovsky JM, Mertes PM. Diagnostic value of histamine and tryptase concentrations in severe anaphylaxis with shock or cardiac arrest during anesthesia. Anesthesiology 2014;121(2):272-279.

39. Böhm I, Speck U, Schild H. A possible role for cysteinyl-leukotrienes in non-ionic contrast media induced adverse reactions. Eur J Radiol 2005;55(3):431-436.

40. Sprung J, Weingarten TN, Schwartz LB. Presence or absence of elevated acute total serum tryptase by itself is not a definitive marker for an allergic reaction. Anesthesiology 2015;122(3):713-714.

41. Valent $\mathrm{P}$, Akin C, Arock M, Brockow K, Butterfield JH, Carter MC, et al. Definitions, criteria and global classification of mast cell disorders with special reference to mast cell activation syndromes: a consensus proposal. Int Arch Allergy Immunol 2012;157(3):215-225.

42. Schwartz LB. Diagnostic value of tryptase in anaphylaxis and mastocytosis. Immunol Allergy Clin North Am 2006;26(3):451-463.

43. Hausmann OV, Gentinetta T, Bridts CH, Ebo DG. The basophil activation test in immediate-type drug allergy. Immunol Allergy Clin North Am 2009;29(3):555-566.

44. Pinnobphun P, Buranapraditkun S, Kampitak T, Hirankarn N, Klaewsongkram J. The diagnostic value of basophil activation test in patients with an immediate hypersensitivity reaction to radiocontrast media. Ann Allergy Asthma Immunol 2011;106(5):387-393.

45. Decuyper, II, Mangodt EA, Van Gasse AL, Claesen K, Uyttebroek A, Faber M, et al. In Vitro Diagnosis of Immediate Drug Hypersensitivity Anno 2017: Potentials and Limitations. Drugs $R D$ 2017;17(2):265-278.

46. Caimmi S, Benyahia B, Suau D, Bousquet-Rouanet L, Caimmi D, Bousquet PJ, et al. Clinical value of negative skin tests to iodinated contrast media. Clin Exp Allergy 2010;40(5):805-810. 
47. Soyyigit S, Goksel O, Aydin O, Gencturk Z, Bavbek S. What is the clinical value of negative predictive values of skin tests to iodinated contrast media? Allergy Asthma Proc 2016;37(6):482488.

48. Joint Task Force on Practice P, American Academy of Allergy A, Immunology, American College of Allergy A, Immunology, Joint Council of Allergy A, et al. Drug allergy: an updated practice parameter. Ann Allergy Asthma Immunol 2010;105(4):259-273.

49. Yamaguchi K, Katayama H, Takashima T, Kozuka T, Seez P, Matsuura K. Prediction of severe adverse reactions to ionic and nonionic contrast media in Japan: evaluation of pretesting. A report from the Japanese Committee on the Safety of Contrast Media. Radiology 1991;178(2):363-367.

50. Higashi TS, Kuniyasu Y, Takizawa K, Ikeuchi T, Kai Y. [The consideration and performing of pretesting of contrast medium: surveying in Kanagawa]. Nihon Igaku Hoshasen Gakkai Zasshi 1993;53(11):1324-1330.

51. Trautmann A, Brockow K, Behle V, Stoevesandt J. Radiocontrast Media Hypersensitivity: Skin Testing Differentiates Allergy From Nonallergic Reactions and Identifies a Safe Alternative as Proven by Intravenous Provocation. J Allergy Clin Immunol Pract 2019;7(7):2218-2224.

52. Jung JW, Choi YH, Park CM, Park HW, Cho SH, Kang HR. Outcomes of corticosteroid prophylaxis for hypersensitivity reactions to low osmolar contrast media in high-risk patients. Ann Allergy Asthma Immunol 2016;117(3):304-309 e301.

53. Mervak BM, Davenport MS, Ellis JH, Cohan RH. Rates of Breakthrough Reactions in Inpatients at High Risk Receiving Premedication Before Contrast-Enhanced CT. AJR Am J Roentgenol 2015;205(1):77-84.

54. Lee SY, Yang MS, Choi YH, Park CM, Park HW, Cho SH, et al. Stratified premedication strategy for the prevention of contrast media hypersensitivity in high-risk patients. Ann Allergy Asthma Immunol 2017;118(3):339-344 e331.

55. Schrijver R DP, Chriac AM. Premedication for iodinated contrast media induced immediate hypersensitivity reactions. Curr Treat Opt Allergy 2019;6:538-553.

56. Greenberger PA, Patterson R. The prevention of immediate generalized reactions to radiocontrast media in high-risk patients. J Allergy Clin Immunol 1991;87(4):867-872. 
57. Lasser EC, Berry CC, Talner LB, Santini LC, Lang EK, Gerber FH, et al. Pretreatment with corticosteroids to alleviate reactions to intravenous contrast material. $N$ Engl J Med 1987;317(14):845-849.

58. Media ACoDaC. ACR Manual on contrast media (available at https://www.acr.org//media/ACR/Files/Clinical-Resources/Contrast_Media.pdf). 2020.

59. Ring J, Rothenberger KH, Clauss W. Prevention of anaphylactoid reactions after radiographic contrast media infusion by combined histamine $\mathrm{H} 1$ - and $\mathrm{H} 2$-receptor antagonists: results of a prospective controlled trial. Int Arch Allergy Appl Immunol 1985;78(1):9-14.

60. Marshall GD, Jr., Lieberman PL. Comparison of three pretreatment protocols to prevent anaphylactoid reactions to radiocontrast media. Ann Allergy 1991;67(1):70-74.

61. Greenberger PA, Patterson R, Tapio CM. Prophylaxis against repeated radiocontrast media reactions in 857 cases. Adverse experience with cimetidine and safety of beta-adrenergic antagonists. Arch Intern Med 1985;145(12):2197-2200.

62. Davenport MS, Cohan RH. The Evidence for and Against Corticosteroid Prophylaxis in AtRisk Patients. Radiol Clin North Am 2017;55(2):413-421.

63. Simons FE, Ardusso LR, Bilo MB, El-Gamal YM, Ledford DK, Ring J, et al. World Allergy Organization anaphylaxis guidelines: summary. J Allergy Clin Immunol 2011;127(3):587-593 e581522.

64. Demoly P, Adkinson NF, Brockow K, Castells M, Chiriac AM, Greenberger PA, et al. International Consensus on drug allergy. Allergy 2014;69(4):420-437.

65. Radiology ESoU. ESUR Guidelines on contrast media (available at http://www.esur.org/fileadmin/content/2019/ESUR_Guidelines_10.0_Final_Version.pdf). 2018. 66. Abe S, Fukuda H, Tobe K, Ibukuro K. Protective effect against repeat adverse reactions to iodinated contrast medium: Premedication vs. changing the contrast medium. Eur Radiol 2016;26(7):2148-2154.

67. Park SJ, Kang DY, Sohn KH, Yoon SH, Lee W, Choi YH, et al. Immediate Mild Reactions to CT with lodinated Contrast Media: Strategy of Contrast Media Readministration without Corticosteroids. Radiology 2018;288(3):710-716. 
68. Soria A, Bernier C, Veyrac G, Barbaud A, Puymirat E, Milpied B. Drug reaction with eosinophilia and systemic symptoms may occur within 2 weeks of drug exposure: A retrospective study. J Am Acad Dermatol 2020;82(3):606-611.

69. Torres MJ, Gomez F, Dona I, Rosado A, Mayorga C, Garcia I, et al. Diagnostic evaluation of patients with nonimmediate cutaneous hypersensitivity reactions to iodinated contrast media. Allergy 2012;67(7):929-935.

70. Schild HH, Kuhl CK, Hubner-Steiner U, Bohm I, Speck U. Adverse events after unenhanced and monomeric and dimeric contrast-enhanced CT: a prospective randomized controlled trial. Radiology 2006;240(1):56-64.

71. Böhm I SH. Immediate and non-immediate reaction after non-ionic X-ray contrast medium injection: case report and review of the literature. Eur J Radiol Extra 2007;61:129-133. 72. Vernassiere C, Trechot P, Commun N, Schmutz JL, Barbaud A. Low negative predictive value of skin tests in investigating delayed reactions to radio-contrast media. Contact Dermatitis 2004;50(6):359-366.

73. Kanny G, Pichler W, Morisset M, Franck P, Marie B, Kohler C, et al. T cell-mediated reactions to iodinated contrast media: evaluation by skin and lymphocyte activation tests. $J$ Allergy Clin Immunol 2005;115(1):179-185.

74. Torres MJ, Mayorga C, Cornejo-Garcia JA, Lopez S, Chaves P, Rondon C, et al. Monitoring non-immediate allergic reactions to iodine contrast media. Clin Exp Immunol 2008;152(2):233238.

75. Hasdenteufel F, Waton J, Cordebar V, Studer M, Collignon O, Luyasu S, et al. Delayed hypersensitivity reactions caused by iodixanol: an assessment of cross-reactivity in 22 patients. $J$ Allergy Clin Immunol 2011;128(6):1356-1357.

76. Gracia-Bara MT, Moreno E, Laffond E, Munoz-Bellido F, Lazaro M, Macias E, et al. Tolerability of iobitridol in patients with non-immediate hypersensitivity reactions to iodinated contrast media. Allergy 2019;74(1):195-197.

77. Ahn YH, Koh YI, Kim JH, Ban GY, Lee YK, Hong GN, et al. The potential utility of iodinated contrast media (ICM) skin testing in patients with ICM hypersensitivity. J Korean Med Sci 2015;30(3):245-251.

This article is protected by copyright. All rights reserved 
78. Böhm I, Medina J, Prieto P, Block W, Schild HH. Fixed drug eruption induced by an iodinated non-ionic X-ray contrast medium: a practical approach to identify the causative agent and to prevent its recurrence. Eur Radiol 2007;17(2):485-489.

79. Gaide O, Emerson RO, Jiang X, Gulati N, Nizza S, Desmarais C, et al. Common clonal origin of central and resident memory T cells following skin immunization. Nat Med 2015;21(6):647653.

80. Gomez E, Ariza A, Blanca-Lopez N, Torres MJ. Nonimmediate hypersensitivity reactions to iodinated contrast media. Curr Opin Allergy Clin Immunol 2013;13(4):345-353.

81. Hari Y, Frutig-Schnyder K, Hurni M, Yawalkar N, Zanni MP, Schnyder B, et al. T cell involvement in cutaneous drug eruptions. Clin Exp Allergy 2001;31(9):1398-1408.

82. Pichler WJ, Tilch J. The lymphocyte transformation test in the diagnosis of drug hypersensitivity. Allergy 2004;59(8):809-820.

83. Kwon OY, Lee JH, Park SY, Seo B, Won HK, Kang Y, et al. Novel Strategy for the Prevention of Recurrent Hypersensitivity Reactions to Radiocontrast Media Based on Skin Testing. J Allergy Clin Immunol Pract 2019;7(8):2707-2713.

84. Rosado A, Canto G, Veleiro B, Rodriguez J. Toxic epidermal necrolysis after repeated injections of iohexol. AJR Am J Roentgenol 2001;176(1):262-263.

85. Romano A, Artesani MC, Andriolo M, Viola M, Pettinato R, Vecchioli-Scaldazza A. Effective prophylactic protocol in delayed hypersensitivity to contrast media: report of a case involving lymphocyte transformation studies with different compounds. Radiology 2002;225(2):466-470.

86. Hunziker T, Kunzi UP, Braunschweig S, Zehnder D, Hoigne R. Comprehensive hospital drug monitoring (CHDM): adverse skin reactions, a 20-year survey. Allergy 1997;52(4):388-393.

87. Courvoisier S, Bircher AJ. Delayed-type hypersensitivity to a nonionic, radiopaque contrast medium. Allergy 1998;53(12):1221-1224.

88. Morales-Cabeza C, Roa-Medellin D, Torrado I, De Barrio M, Fernandez-Alvarez C, MontesAcenero JF, et al. Immediate reactions to iodinated contrast media. Ann Allergy Asthma Immunol 2017;119(6):553-557.

89. Gracia Bara MT, Moreno E, Laffond E, Munoz FJ, Macias E, Davila I. Selection of contrast media in patients with delayed reactions should be based on challenge test results. J Allergy Clin Immunol 2012;130(2):554-555; author reply 555-556. 
90. Collins MS, Hunt CH, Hartman RP. Use of IV epinephrine for treatment of patients with contrast reactions: lessons learned from a 5-year experience. AJR Am J Roentgenol 2009;192(2):455-461.

91. Lightfoot CB, Abraham RJ, Mammen T, Abdolell M, Kapur S, Abraham RJ. Survey of radiologists' knowledge regarding the management of severe contrast material-induced allergic reactions. Radiology 2009;251(3):691-696.

92. Gaca AM, Frush DP, Hohenhaus SM, Luo X, Ancarana A, Pickles A, et al. Enhancing pediatric safety: using simulation to assess radiology resident preparedness for anaphylaxis from intravenous contrast media. Radiology 2007;245(1):236-244.

93. Yang MS, Choi SI, Song WJ, Kim SH, Kang HR, Park HW, et al. Impact of an electronic consultant system on hypersensitivity reactions to iodinated radiocontrast media: an observational study. Postgrad Med J 2015;91(1074):193-199.

94. Bae YJ, Hwang YW, Yoon SY, Kim S, Lee T, Lee YS, et al. The Effectiveness of Automatic Recommending System for Premedication in Reducing Recurrent Radiocontrast Media Hypersensitivity Reactions. PLoS One 2013;8(6):e66014.

95. Brockow K, Jofer C, Behrendt H, Ring J. Anaphylaxis in patients with mastocytosis: a study on history, clinical features and risk factors in 120 patients. Allergy 2008;63(2):226-232.

96. Macy EM. Current Epidemiology and Management of Radiocontrast-Associated Acuteand Delayed-Onset Hypersensitivity: A Review of the Literature. Perm J 2018;22:17-072.

97. Carter MC, Metcalfe DD, Matito A, Escribano L, Butterfield JH, Schwartz LB, et al. Adverse reactions to drugs and biologics in patients with clonal mast cell disorders: A Work Group Report of the Mast Cells Disorder Committee, American Academy of Allergy, Asthma \& Immunology. J Allergy Clin Immunol 2019;143(3):880-893.

98. Mervak BM, Cohan RH, Ellis JH, Khalatbari S, Davenport MS. Intravenous Corticosteroid Premedication Administered 5 Hours before CT Compared with a Traditional 13-Hour Oral Regimen. Radiology 2017;285(2):425-433. 


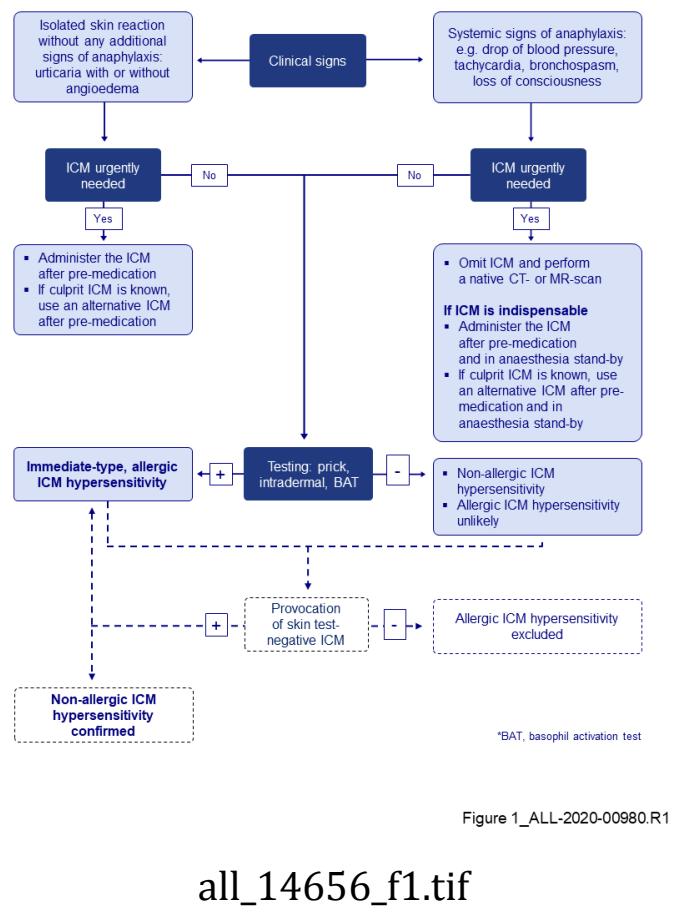

This article is protected by copyright. All rights reserved 


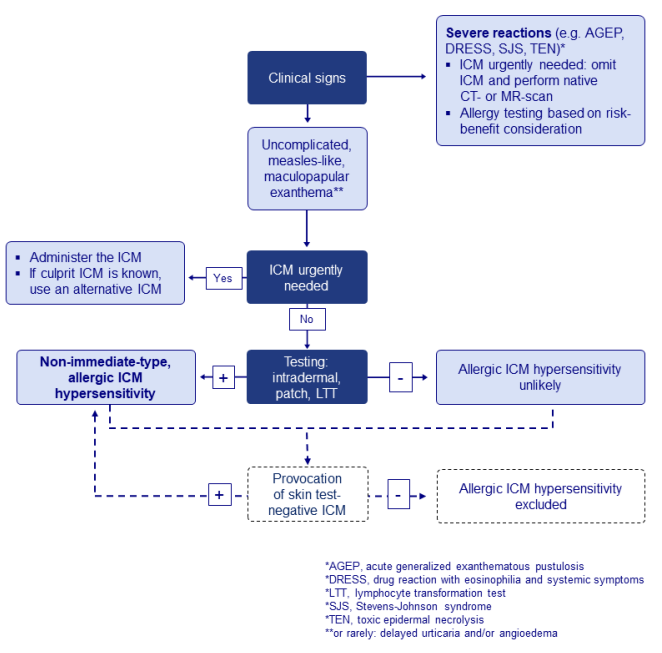

Figure 2_ALL-2020-00980.R1

all_14656_f2.tif 